\title{
Building the future together
}

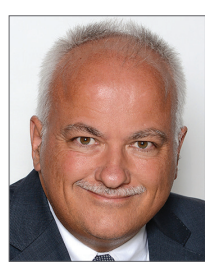

Michael Haude, MD, President EAPCI

Medical Clinic I, Städtische Kliniken Neuss, Lukaskrankenhaus GmbH, Neuss, Germany
The last 12 months have witnessed the steady growth of our Association. In keeping with the two-year cycles we instituted for the administration of the EAPCI, the chairs and co-chairs of the different committees changed at the same time that the presidency was passed on from Stephan Windecker to myself. This was done, as always, in a spirit of continuity - a moment to expand our horizons while re-dedicating ourselves to the basic goals of our Association and profession as a whole. We all benefit from the strong commitment of our members, past and present, and it should not be forgotten that the time and effort individuals devote to the work of EAPCI committees is essential to the overall success the Association enjoys.

The year 2016 has seen a renewal along these lines with an expansion of our ability to communicate and interact with our members, with a renewed commitment to women, to young interventionalists and to nurses and allied professionals. We have increased our offering of Fellowship grants and remain vigilant and proactive with regard to the welfare of our members through programmes of continuing education and by addressing issues that affect our membership.

In earlier editorials we spoke about the importance of the new EAPCI constitution and the effect it will have on further integration with our parent organisation, the European Society of Cardiology (ESC). The dedicated staff of the EAPCI at the ESC are an essential link in the life of our Association, bringing, among other things, the expertise of the ESC to the EAPCI website. This is also true of the staff who work with us on PCRonline or produce our official publication, EuroIntervention. The EAPCI gains by the quality of the exposure and interactivity offered us.

Along these lines, next year will see a continued expansion of EAPCI activities, among which will be a special "National Registries" supplement dedicated to the National Societies, a closer look at what is being accomplished in many of our individual member countries.

An association exists for and is defined by its membership. It is not the action of one officer or one member that can make a difference, but of all of us working together to advance our common commitment to patient care. As President, I am acutely aware of and grateful for the commitment of us all, but I want to cite especially the Board members and committee chairs and co-chairs who believe in what the EAPCI stands for and are willing to give of their time to make it the dynamic association we have today. As this year comes to an end I want to take a moment to thank them, and every one of you who has made the continued success of the EAPCI possible.

On behalf of the EAPCI, I wish you all a very happy holiday season and look forward to what we can - and will - accomplish together in the coming year.

*Corresponding author: Medical Clinic I, Städtische Kliniken-Neuss, Lukaskrankenhaus GmbH, Preußenstr. 84, 41464 Neuss, Germany.E-mail:mhaude@lukasneuss.de 